\title{
Back-trap Mottle: A Review of Mechanisms and Possible Solutions
}

\author{
Hak Lae Lee, ${ }^{\mathrm{a}, \mathrm{b}, *}$ Hye Jung Youn, ${ }^{\mathrm{a}, \mathrm{b}}$ Ming He, ${ }^{\mathrm{b}}$ and Jiachuan Chen ${ }^{\mathrm{b}}$ \\ Print mottle is a serious and common uneven printing defect that occurs \\ when printing coated paper by the offset multicolor printing process. It is \\ characterized by a non-uniform appearance in terms of brightness, gloss, \\ or color density that appears mostly in solid printed areas. Back-trap print \\ mottle and water-interference print mottle occur when the quality of the \\ paper substrate, especially the coating layer quality, is not satisfactory. To \\ cope with this quality problem of coated papers, the understanding of the \\ offset printing process, the requirements of coated-paper quality, and the \\ reasons for this problem should be addressed. In this review, the basic \\ process of offset printing and the mechanisms of print mottles were \\ explored, the importance of coating uniformity in both the coating structure \\ and process was reviewed, and the approaches to cope with print mottle \\ were introduced.
}

Keywords: Print mottle; Back-trap; Offset printing; Coating structure; Coating thickness; Binder migration; Drying

Contact information: a: Program in Environmental Materials Science, Department of Agriculture, Forestry, and Bioresources, and Research Institute of Agriculture and Life Sciences, College of Agriculture and Life Sciences, Seoul National University, 1 Gwanak-ro, Gwanak-gu, Seoul 08826 Korea; b: State Key Laboratory of Biobased Material and Green Papermaking, Qilu University of Technology (Shandong Academy of Sciences), Jinan 250353 China; *Corresponding author: Ihakl@snu.ac.kr

\section{INTRODUCTION}

Most types of papers, including printing and writing grades, as well as packaging grades, undergo a printing process. Therefore, printability is a crucial factor that determines the quality of most paper products (Paltakari et al. 2009). As multicolor printing has become a common printing method, the use of coated paper or coated board (hereinafter collectively referred to as coated paper) with excellent appearance and printability has become a common practice. This is because coated paper provides excellent whiteness, opacity, and gloss compared with uncoated paper, in addition to excellent print color density, dot reproducibility, ink holdout, print gloss, and many other advantages in printing. However, coated paper is susceptible to printing defects, such as picking (dry and wet picking), ink set-off, and mottling, which are more frequent in coated papers than in uncoated papers. Among these printing defects, print mottle is one of the most serious and most frequently occurring printing defects, and one of the main determinants of the quality of print when printing coated paper by the offset multicolor-printing process (Lyne 1979; Vanya 1989; Kim et al. 1998; Xiang et al. 2000; Kline et al. 2011a,b). Gumbel (2003) pointed out that print mottle is a serious print quality problem that causes $42 \%$ of the print quality complaints for coated woodfree paper in Europe.

Mottling is an uneven printing defect characterized by a spotty, low-contrast, lowfrequency, and non-uniform appearance, i.e., small dark and light areas (Fig. 1). It occurs mostly in solid print areas because uneven printing density or gloss can be easily seen on 
an image with a large area of homogenous tone. The definition of print mottle in the ISO 13660 (2001) standard states that a periodic fluctuation of the print density at a frequency of 0.4 cycles/mm or less in all directions is print mottle (Fahlcrantz and Johansson 2004; Xu et al. 2016), with low-contrast and low-frequency $(0.1$ to $10 \mathrm{~mm})$ printing unevenness. Näätsaari (2006) showed that the mottling in the frequency range of 2 to $7 \mathrm{~mm}$ is the most disturbing to the human eye. This visible non-uniformity may be the result of differential ink gloss, density, or color of the printed ink film, or due to randomly connected and disconnected mid-tone dots.

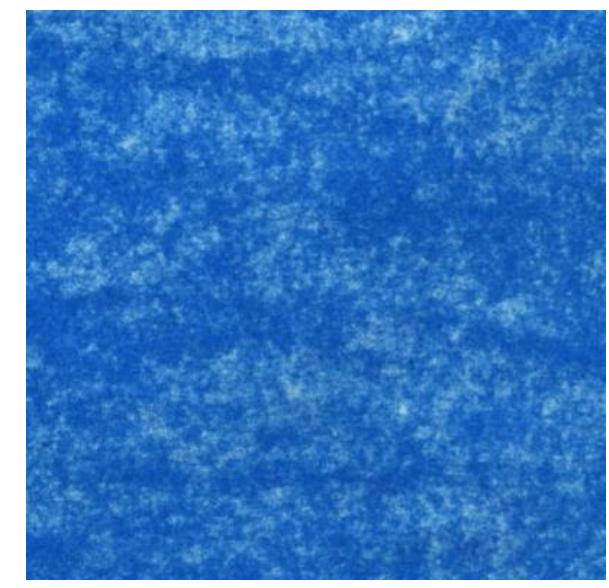

Fig. 1. An example of print mottle. (https://www.ri.se/en/what-we-do/services/stfi-mottling-expertsoftware)

\section{TYPES OF PRINT MOTTLE}

The various types of print mottles are distinguished by the characteristic that is affected, e.g., density mottle, opacity mottle, brightness mottle, gloss mottle, and color mottle (Sandreuter 1994). Opacity and brightness mottle occur when an uneven coating weight is applied by blade coating on uneven base paper, because the coating color typically has better optical properties than the base paper. Contour coating on uneven base paper tends to impart uneven gloss after calendering, because peak and valley areas tend to be high and low in gloss, respectively (Anttila et al. 2009).

It is more common to describe print mottle in terms of its cause rather than in terms of the non-uniform properties it generates in paper (Klein et al. 2011a,b). There are several causes of print mottling, and they involve many parameters, including the type of ink, the printing press operation, and, most importantly, the properties of the paper. Based on mechanics, four types of mottling can be identified: printer's mottle, ink-trap mottle, backtrap mottle, and water-interference mottle (Saini et al. 2016a, 2016b).

\section{Printer's Mottle and Ink-trap Mottle}

Printer's mottle often occurs when a misconfigured printing press transfers an inconsistent layer of ink film to the substrate. In general, printer's mottle usually occurs due to incorrect printing conditions. For example, in addition to a misconfigured press and an incorrectly set-up ink train, fountain solution, ink, or plate can lead to the transfer of an inconsistent layer of ink film to the paper, creating printer's mottle. Ink-trap mottle occurs 
in multiple printing nip units when the tack of the ink in the previous nip is too low to trap the ink in the subsequent nip. These two types of print mottles have no relationship with the characteristics of the substrate. If the mottle persists even after the printer flips the sheet or tries another brand of paper of equal grade, it may be described as printer's mottle or ink-trap mottle.

Occasionally, print mottling is entirely due to the characteristics of the paper. For example, some paper may have a mottled appearance after printing while others do not, even when the same printing ink and printing conditions are used. In such cases, the paper is the obvious source of the print mottle (Lee 2008). For example, back-trap mottle and water-interference mottle are directly influenced by the properties of the substrate (Eby and Whalen-Shaw 1991). Some studies have investigated the relationship of coating properties with back-trap mottle and water-interference mottle (Purfeerst and van Gilder 1991; Lie and Kolseth 2007).

\section{Back-trap Mottle and Fountain Water Mottle}

Back-trap mottle is the most common type of print mottle and is typically the result of non-uniform ink absorbency across the surface of printed paper, which leads to uneven immobilization of the ink, non-uniform tack buildup, and splitting of the ink (KimHabermehl et al. 1998; Xiang et al. 1999, 2000; Engström 2016; Thorman et al. 2018). This results in a non-uniform ink transfer from the contact print image on the paper surface to the following printing blanket of the next printing units, which causes further uneven contact with the following paper surface throughout the subsequent printing units (Thorman et al. 2018). Several research groups have reported the relationship between back-trap mottle and non-uniform surface porosity (i.e., the distribution of pores and clustering of closed areas) in paper (Kim-Habermehl et al. 1998; Xiang et al. 2000; Chinga and Helle 2003; Shen et al. 2005; Preston et al. 2008).

Water-interference mottle, which is also called fountain-water mottle, wet-trap mottle, water-repellence mottle, or ink-refusal mottle, is caused by insufficient and uneven fountain-water absorption by paper, followed by uneven ink absorption (Arai 1989; Shen et al. 2005). These two types of print mottle demonstrate the importance of having a uniform paper surface that allows uniform absorption of ink and fountain water (Kasajová and Gigac 2020).

Many studies have investigated print mottling, but some studies have reported contradictory results and interpretations. This suggests the need for further research on print mottling, and that the mottling phenomenon is influenced by a wide variety of factors. In this review, the cause of print mottle and the relationship between print mottle and the quality characteristics of the coated paper are discussed, after a brief introduction of the offset printing process.

\section{OFFSET PRINTING PROCESS}

Offset printing, also called offset lithography, or litho-offset in commercial printing, is a widely used printing technique that was established at the end of $18^{\text {th }}$ century by Alois Senefelder, a German map inspector (Anayath and Baral 2016). An offset printer is composed of a plate cylinder, a blanket cylinder, and an impression cylinder (Hakola 2009). A printing plate is attached to the plate cylinder, an offset rubber blanket is attached to the blanket cylinder, and the impression cylinder is used to carry the paper through the 
printing unit and to provide a hard backing against which the blanket can impress an image on the paper.

On the printing plate for offset printing, the image area and the non-image area exist on the same plane. The image area of the offset printing plate is hydrophobic, whereas the non-image area is hydrophilic (Bruno and Walker 1983). Thus, the image area of the lithographic printing plate has a high affinity for non-polar (hydrophobic) ink, whereas the non-image area has a high affinity for fountain water (Bassemir 1982). These chemical principles ensure that the ink will only adhere to the image areas of the plate.

Table 1 shows that the polar surface energy of the image area is noticeably lower than that of the non-image area and is similar to that of the ink. In addition, Table 1 shows that the polar surface energy of the image area exceeds that of the ink itself after ink application, because a small amount of fountain solution is emulsified into the ink on the printing press.

Table 1. Surface Energies of the Printing Plate and Ink Surfaces (Bassemir 1982)

\begin{tabular}{|c|c|c|c|}
\hline Area & $\begin{array}{c}\text { Total Surface Energy } \\
\text { (Dynes/cm) }\end{array}$ & $\begin{array}{c}\text { Nonpolar Surface } \\
\text { Energy } \\
\text { (Dynes/cm) }\end{array}$ & $\begin{array}{c}\text { Polar Surface Energy } \\
\text { (Dynes/cm) }\end{array}$ \\
\hline Image area & 44.9 & 34.7 & 10.2 \\
\hline Nonimage area & 76.5 & 34.7 & 41.8 \\
\hline Ink & 33.5 & 27.7 & 5.8 \\
\hline $\begin{array}{c}\text { Inked image area of } \\
\text { plate }\end{array}$ & 41.2 & 29.8 & 11.4 \\
\hline
\end{tabular}

The plate cylinder with the printing plate is equipped with a number of rolls to apply the fountain solution (or dampening solution) and ink. The fountain solution containing a solution of gum arabic, or other gum compound, is applied to the printing plate before the application of the ink (MacPhee 1979; Bruno and Walker 1983). When the printing plate contacts the dampening rollers, the hydrophilic non-image area is uniformly covered with a thin layer of fountain solution. The hydrophobic image area, however, repels the fountain solution; thus no fountain solution is retained in the image area. Occasionally, however, small droplets of the fountain solution may remain on the image area. Subsequently, when the printing plate is passed through the ink rolls, ink is applied from the ink train to the hydrophobic image areas of the printing plate, and the image area is covered with an ink film approximately 1 to $3 \mu \mathrm{m}$ thick (Hakola 2009; Pang et al. 2015). However, ink cannot be transferred to the non-image area covered with the fountain solution, due to the repulsion between the ink and the fountain solution, i.e., the fountain solution prevents the ink from transferring to the non-image area of the printing plate (Lovreček et al. 1998). The inked image on the printing plate is printed on a rubber cylinder before it is transferred (i.e., offset) to paper or other material. When the printing plate comes into contact with the rubber blanket, the ink and fountain solution are transferred to the blanket. The fountain water on the printing area, however, breaks up and forms droplets, because of the hydrophobic character of the blanket (Engström 1994). Finally, the ink and fountain solution on the rubber blanket are transferred to paper, completing the printing of one color.

The rubber blanket is soft and therefore highly flexible, permitting good printing on rough paper, wood, cloth, and leather (e.g., Encyclopedia Britannica covers). The rubber 
blanket not only allows a good transfer of ink to diverse substrates, but also plays a role in reducing the wear of the printing plate by rough paper or other substrates. In four-color printing, separate black, cyan, magenta, and yellow inks are successively applied to give the best print quality (Engström 1994). In some cases, the order of black and cyan is swapped for printing.

\section{MECHANISM OF MOTTLING}

\section{Back-trap Mottle}

When a printed paper from a printing unit is fed to the next printing unit and contacts the inked rubber blanket, a part of the previously printed ink is retransferred to the blanket. This phenomenon occurs only when the pre-printing ink located in the image area contacts the non-image area at the next printing nip. Because the blanket is made of rubber, it is hydrophobic. Therefore, on the surface of the blanket corresponding to the non-image area, the fountain solution does not exist in the form of a film (as on the printing plate) but is deformed into droplets or irregular shapes. Thus, the fountain solution that exists as a uniform film on the hydrophilic non-image area of the printing plate loses its uniformity when it is transferred to the blanket. Therefore, the non-image area on the blanket is not covered by the dampening solution in which the ink from the previous color unit is retransferred (i.e., back-trapped) from the printed paper.

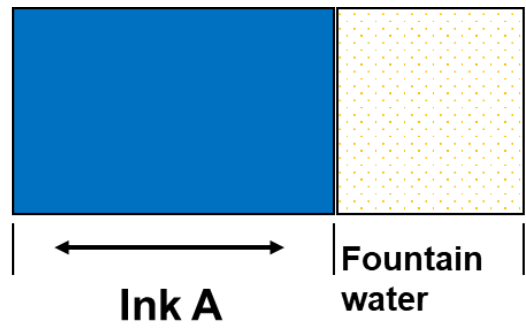

Blanket

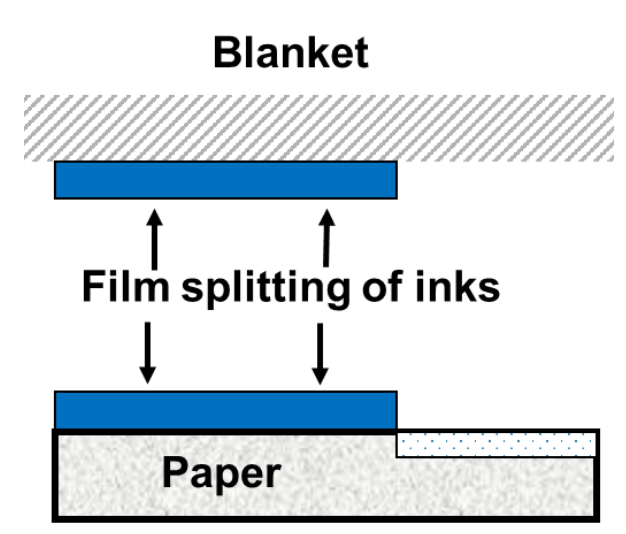

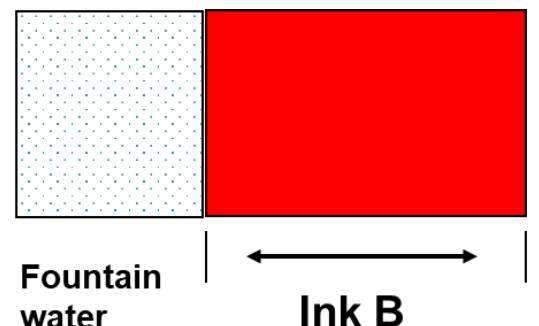

water

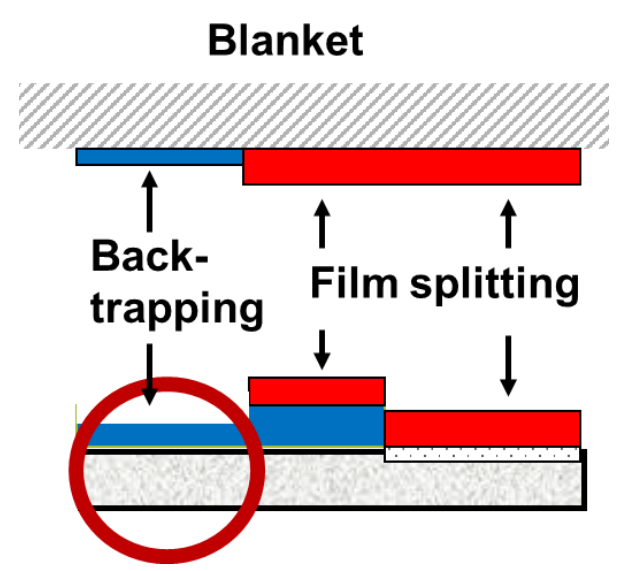

Fig. 2. Schematic diagram demonstrating the mechanism of back-trapping in wet offset printing. The cyan ink on the printing plate (Ink A) transfers to the rubber blanket and finally to the paper. In the next printing unit, which applies magenta ink (Ink B), the ink similarly transfers from the plate to the paper via the blanket. However, some of the cyan ink on the paper is back-trapped to the blanket. The amount of back-trapped ink may not be uniform, and this results in back-trap mottling. 
When the printing ink on the paper contacts the image area on the next printing unit, the over-printing ink on the blanket is transferred onto the under-printed ink on the paper. The opposite process, i.e., the transfer of the under-printed ink back to the image area on the blanket of the over-printing unit, does not occur. This is because the tack value (i.e., the resistance of an ink film to splitting) of the previous printing ink is higher than that of the next printing ink (Oittinen 1976; Voltaire 2004). The concepts explained thus far are shown schematically in Fig. 2. In multi-color printing, the first printed ink transfers to the second, third, and fourth printing blankets. The final thickness of the ink remaining on the paper varies, according to how much ink is back-trapped by the blanket.

If the ink absorption of the printed surface is uniform, the amount of back-trapped ink will be uniform across the surface, and thus no mottling occurs. If the ink transferred from the first printing unit is completely set before the printed paper is fed to the next color unit, back-trapping does not occur at all (Oittinen and Saarelma 2009). However, the dwell time between the printing units of the lithographic printing press is short (usually $\leq 0.2 \mathrm{~s}$, or up to a few s at maximum, depending on the configuration of the printing press) (Kolseth 2009). Furthermore, complete setting of the ink cannot occur, due to the absence of a dryer between the printing units (Hakola 2009).

The ink absorption characteristics of coated paper differ considerably from place to place on the paper surface. Thus, the point-by-point variation in the ink-setting rate correlates with the back-trap mottle problem on coated paper (Xiang et al. 1999; Lee 2008). With an increase in printing speed, ink absorption between printing units is greatly reduced. If the ink-absorption properties of the printed surface vary from place to place on the paper surface, the phenomenon shown in Fig. 3 occurs. That is, the moment the ink is transferred from the offset blanket to the paper (Fig. 3), the thickness of the ink on the paper is almost uniform.

The ink transferred to the paper starts to penetrate the paper by capillary action. In areas with smaller pores on the surface of the printed paper, the penetration rate of the ink vehicle is slower than that in areas with larger pores (Lee 1992; Lee et al. 1997). Therefore, during the dwell time before the next printing nip, greater penetration of the ink vehicle occurs in areas with larger pores, and less occurs in areas with smaller pores. That is, ink setting proceeds over a considerable thickness in areas with larger pores, but not in areas with smaller pores. The tack and viscosity of ink increases as the penetration of the ink vehicle increases. Immobilized ink is not affected by film splitting and tends to remain on the paper surface, and it does not transfer back or become back-trapped to the blanket of the next printing unit.

Because approximately half of the non-immobilized ink is transferred back to the blanket of the next printing press by film splitting, greater back-trapping of the ink occurs in areas with smaller pores, where the absorption of the ink vehicle is low, than in areas with larger pores (Anttila et al. 2009; Kolseth 2009). This results in the retention of a thinner ink film in areas with smaller pores than in areas with larger pores. Thus, the ink density in areas with smaller pores is lower than that in areas with larger pores, because a small amount of ink remains after back-trapping. Ozaki et al. (2008) showed that an uneven ink-varnish distribution leads to back-trap mottle, and that there is little varnish penetration in regions with a thin-coated layer.

In general, the color that is printed in the first unit of the press shows the most backtrap mottling. Thus, as cyan ink is typically the first color printed (black, cyan, magenta, and then yellow is a common order), most back-trap mottling is observed in cyan printing (Whalen-Shaw and Eby 1991). In contrast, black ink does not show back-trap mottling 
because it is run on a press at an ink film thickness that is 1.5 to 2.0 times greater than that of the three process colors, and it has slower setting characteristics (Plowman 1994). A last-down yellow ink cannot back-trap, as it does not contact any subsequent blankets in the press.

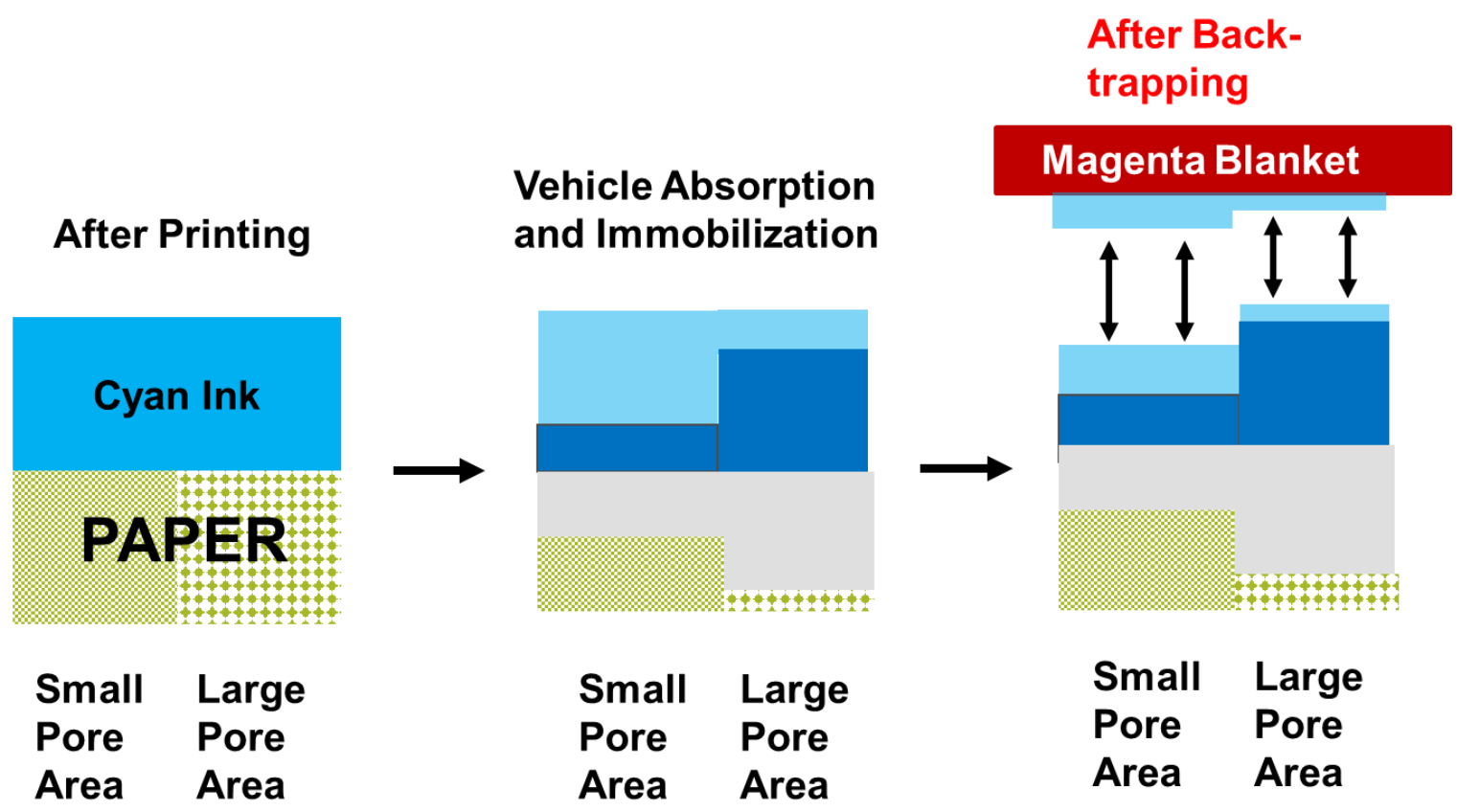

Fig. 3. The difference in ink absorption between two areas with different porosity. An area with small pores absorbs a small amount of ink, which results in a low retention of ink after backtrapping. In contrast, an area with large pores has a greater retention of ink after ink immobilization before back-trapping, which results in a thicker ink film and a higher ink density.

\section{Water-interference Mottle}

Water-interference mottle results from the imbalance between the amount of fountain solution or dampening solution applied to the paper surface and the ability of the paper to absorb this (Plowman 1994; Lie and Kolseth 2007; Preston et al. 2008; Thorman et al. 2018). Water-interference mottle can occur when only a single printing unit is used and with any ink formulation. For example, a single-color press that prints only black can exhibit severe water-interference mottle, and a multi-color press can exhibit this type of mottle in every ink color.

Water-interference mottle is most objectionable in screen areas and halftone pictures (Plowman 1994). Water-interference mottle frequently occurs when the water applied to the paper in one of the printing units is not absorbed by the paper before it reaches a subsequent printing unit (Aspler and Lepoutre 1991). Water-interference mottle occurs more frequently in the satellite press because the distance between the printing units is shorter for the satellite press than the presses arranged in a series (Engström 1994). Arai (1989) showed that non-uniform absorption of fountain solution causes print mottle, which corresponds directly to the non-uniformity of the surface distribution of binders and pigments. 


\section{FACTORS ASSOCIATED WITH BACK-TRAP MOTTLE}

\section{Coating Structure}

The influence of coating structure on printing properties has been investigated in a number of studies (Zang and Aspler 1995; Donigian et al. 1997, 2004; Lee et al. 1997; Chinga and Helle 2003; Resch et al. 2010), and many studies have shown that non-uniform surface porosity is an important factor for back-trap mottle (Kim-Habermehl et al. 1998; Xiang et al. 2000; Chinga and Helle 2003; Shen et al. 2005). Engström (2016) and Xiang et al. (1999) showed that non-uniform pore structure of the coating causes uneven inkvehicle absorption to the coating, which results in uneven ink split in the printing nip and causes back-trap mottle ( $\mathrm{Li}$ and Li 2014; Alm et al. 2015). As the pore size is a principal factor for ink setting rates, the non-uniform pore size distribution on the coating surface is the prime cause of print density mottle (Preston et al. 2008). Non-uniformity of the coating structure and coating weight distribution, especially the binder distribution, has also been shown to be a major causative factor in back-trap print mottle (van Gilder and Purfeerst 1994; Chinga and Helle 2003; Kenttä et al. 2006; Engström 2016).

Local variations in coat weight have been shown to greatly influence back-trap mottle (Engström et al. 1991; Whalen-Shaw and Eby 1991; Engström 1994, 2016; Kenttä et al. 2006; Ozaki et al. 2008; Ragnarsson et al. 2013). This influence is attributable to the fact that mottled areas with a low ink density have a higher concentration of latex on their surfaces, which is caused by the greater mean coating thickness and mean raw stock roughness in these areas compared to those with a high ink density (Whalen-Shaw and Eby 1991). In general, an increase in the coat weight leads to an increase in binder migration to the surface layer. Therefore, when a thick part and a thin part of the coating layer coexist on the same coating surface, the content of the surface binder is higher in the part with the higher coat weight (i.e., the thick part). This is because more moisture evaporates from the surface of the higher coat-weight area during the drying process than from the lower coatweight area, and thus a larger amount of the binder migrates to the surface layer with the evaporating water in the former area (Whalen-Shaw and Eby 1991).

\section{Base Paper Formation and Roughness}

Variations in coat weight occur due to the irregularities of the base paper, and this is reported as the main cause of non-uniform coating (Gane 1989; Tomimasu et al. 1990; Matsubayashi and Saito 1992). This phenomenon is more common when a level coating is applied with a blade coater than when a contour coating is applied with an air-knife coater. A high blade pressure during the coating application that increases the water penetration to the paper, the use of compressible base papers, and an increased water pick-up between application and metering (i.e., a long dwell coating) plasticize the paper and improve the uniformity of the mass distributions of coatings (Engström 2016). However, these parameters may have a detrimental effect on the runnability during blade coating in terms of web breaks.

Dahlström and Uesaka (2012) show that the mass density of the underlying base sheet greatly affects the porosity of the relatively bulky clay/GCC (ground calcium carbonate) coating, but that this is not so for a more compact clay coating. Additionally, they show that areas with more fibers in the base sheet are more compressed by calendering, resulting in a decreased coating porosity, which contributes to mottle in offset printing. 
Therefore, to minimize print mottle, it is necessary to find a way to minimize the variation in the binder content of the surface layer by preventing the variation in coat weights and coating structure.

\section{Binder Migration}

Binder migration has been defined as "a differential movement of a binder or binders with respect to pigment particles, leading to non-uniform binder distributions in coated paper and paperboard" (Lee and Whalen-Shaw 1993). Binder migration within a coating has also been a subject of research for many years, and a good literature review of this research topic was conducted by Whalen-Shaw (1993).

The binder in a coating color moves to the surface of a coating layer or down to the paper surface during the drying of the coating color. This results in an uneven distribution of binder inside the coating layer, with more binder on the coating surface or the coatingpaper interface, thereby forming a binder-enriched layer. Dahlström and Uesaka (2012) found that a binder-enriched area may be less than $500 \mathrm{~nm}$ thick at the coating surface, and at the coating-paper interface (Fig. 4). When this occurs, there is insufficient binder present in the center of the coating layer, which reduces the binding force inside the coating layer and consequently reduces the coating strength and causes a picking phenomenon during printing (Dappen 1951; Engström 1994). Moreover, the characteristics of the coating surface, including the surface energy and liquid absorption, also change because the latex binder, which is more hydrophobic than the pigments and fills the voids between the pigments (Järnström et al. 2010). In addition, a print mottle phenomenon may occur due to the uneven distribution of binder on the surface. Furthermore, with increasing amounts of latex, the absorption time generally increases, probably due to the additional latex decreasing the porosity of the paper (Järnström et al. 2010).

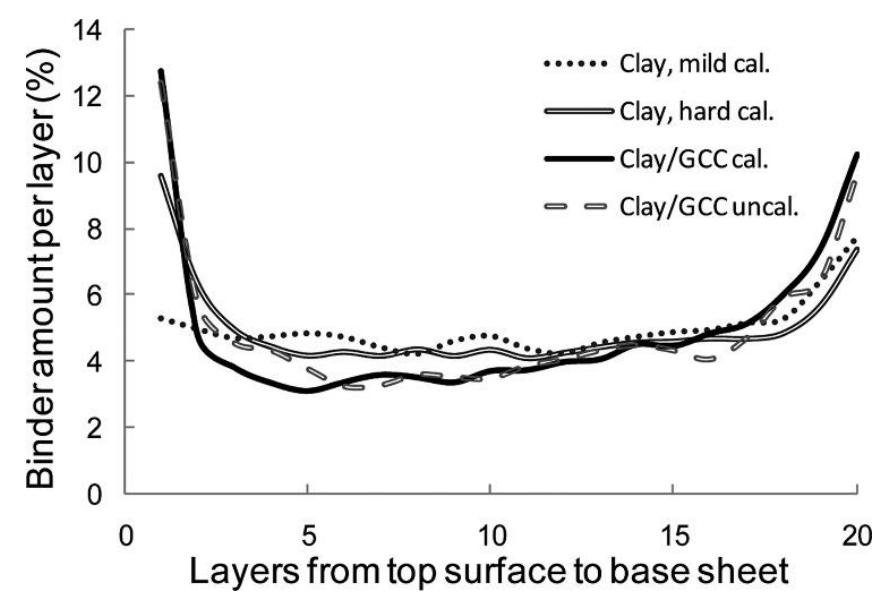

Fig. 4. Binder amount is distributed from the coated surface down to the base sheet, divided into 20 layers. Types of pigment and calendaring influence the binder distribution (Dahlström and Uesaka 2012).

\section{Factors that influence binder migration}

Several factors, such as the type of binder and pigment, the solid contents of the coating color, the absorption property of the base paper, the drying rate, and the use of water retention aids, influence binder migration (Whalen-Shaw 1993). Yamazaki et al. (1993) showed that starch and latex have different migration behavior during the consolidation process of coating. Compared with latex, starch migrates more easily toward 
the base sheet or the coated surface and has more influence on print mottling of the coated paper. The roles of pigment in dewatering and binder migration have been reported by Lee (1992) and Baumeister and Kraft (1980). It was shown that the dewatering rate from the pigment suspension is inversely proportional to the square of the specific surface area of pigments, and a greater migration of binders may occur for the lower-surface area pigment coatings. Di Risio and Yan (2006) found a correlation between the arrangement of the binder microdomains within the paper-coating layer and the packing ability of the pigments. They showed that the size distribution of pigment particle strongly influenced the uniformity of binder configuration even for the coating layer without any binder migration. In other words, coarser pigments tend to give larger microdomains of binders with a greater local variability than less coarse pigments.

The dewatering of the coating color to the base substrate also influences binder migration. Base papers with larger pores and higher water absorptivity exhibit greater binder migration (Krishnagopalan and Simad 1976; Eklund and Salminen 1986; Salminen et al. 1995). A higher binder migration into the base paper results in greater dusting and picking during printing. This is because areas with low binder exist within the coating layer. The importance of drying rate in binder migration and print mottling has been highlighted by Ashan (1986), Hagen (1986), Norrdahl (1991), Bushhouse (1990), and Backfolk et al. (2006). They showed that uneven binder migration toward the coating surface results in uneven binder contents at the surface and eventually print mottling due to the uneven ink transfer and water and ink absorption.

\section{Evaluation of binder migration}

The uniformity of the binder contents and distribution within the coating layer have been associated with print quality. Because printing defects, such as mottling, are closely associated to the uniformity in binder distribution, diverse methods have been applied to analyze the spatial distribution of the binder within a coating layer (Groves et al. 2001). The techniques summarized in Table 2 can be divided into three groups: electron microscopy, chemical spectroscopy, and scanning probe microscopy. Although diverse efforts have been made to evaluate the factors that influence the spatial binder distribution in the coating layer, the factors that govern this remain contradictory (Di Risio and Yan 2006).

Traditionally, the binder and pigment concentrations at the top surface of coated paper have been quantified by X-ray photoelectron spectroscopy, often called electron spectroscopy for chemical analysis (ESCA) (Tomimasu et al. 1986; Arai et al. 1988; Ström and Carlsson 1993). Other spectroscopy methods, such as UV absorption spectroscopy (Fujiwara and Kline 1987; Klein 1988, 1991) and Fourier transform infrared/attenuated total reflectance-infrared (FTIR/ATR-IR) spectroscopy (Halttumen et al. 2001), were not successful in determining the amount of latex in the coating surface or the correlation of print mottle and binder distribution on the surface, due to their limited surface sensitivity. Bitla et al. (2003) and Vyörykkä et al. (2001, 2004a,b) have shown that confocal Raman microscopy provides excellent compositional maps of coating layers at a resolution of 2 $\mu \mathrm{m}$ in planar dimensions. In general, spectroscopic techniques detect no distinct chemical differences between two samples, where one has serious back-trap mottle and the other has no back-trap mottle. This is probably because these techniques focus on analyzing deeper layers of the structure to identify surface non-uniformities. Likewise, ESCA does not clarify the relationship between print mottle and the surface structure of coated paper, due to the limitation of its resolution (Fardim and Holmbon 2003; Zhen and Wang 2013). 
Table 2. Methods Used to Evaluate Binder Migration and Distribution in the Coating Layer

\begin{tabular}{|c|c|c|}
\hline Method & Measured Item & Citation \\
\hline UV spectroscopy & UV absorption of SB latex & Fujiwara and Kline (1987) \\
\hline UV spectroscopy & SB latex distribution on the surface & Kline (1988) \\
\hline UV spectroscopy & SB latex migration & Kline (1991) \\
\hline FTIR/ATR-IR & Latex content in the coating & Kenttä et al. (2000) \\
\hline FTIR/ATR-IR & $\begin{array}{l}\text { SB latex distribution at the coating } \\
\text { surface }\end{array}$ & Halttumen et al. (2001) \\
\hline FTIR/ATR-IR & $\begin{array}{l}\text { Latex distribution in the coating } \\
\text { layer }\end{array}$ & Kenttä et al. (2006) \\
\hline Raman spectroscopy & Binder depth profile & Vyörykkä et al. (2001) \\
\hline Raman spectroscopy & $\begin{array}{c}\text { Effect of GCC particle size on latex } \\
\text { migration }\end{array}$ & Bitla et al. (2003) \\
\hline Raman microscopy & $\begin{array}{c}\text { Mapping of chemical and physical } \\
\text { composition }\end{array}$ & Vyörykkä et al. (2004) \\
\hline $\begin{array}{l}\text { Confocal Raman } \\
\text { microscopy }\end{array}$ & $\begin{array}{c}\text { Depth profiles of coated and printed } \\
\text { papers }\end{array}$ & Vyörykkä et al. (2004) \\
\hline ESCA & $\begin{array}{c}\text { Chemical composition of the coated } \\
\text { surface }\end{array}$ & $\begin{array}{c}\text { Ström and Carlsson } \\
(1993)\end{array}$ \\
\hline ESCA & Surface binder concentration & Tomimasu et al. (1986) \\
\hline ESCA & Surface profile of the binder & Arai (1989) \\
\hline ESCA, ToF-SIMS, FE-SEM* & $\begin{array}{l}\text { Distribution of papermaking } \\
\text { chemicals }\end{array}$ & $\begin{array}{l}\text { Fardim and Holmbon } \\
(2003)\end{array}$ \\
\hline SEM-EDXA * and ESCA & $\begin{array}{l}\text { Effects of drying temperature and } \\
\text { pigment types on binder migration }\end{array}$ & Zhen and Wang (2013) \\
\hline ToF-SIMS * & Analysis of the coating surface & Zimmerman et al. (1995) \\
\hline SEM and image analysis & Coating structure characterization & Chinga and Helle (2002a) \\
\hline SEM and image analysis & Coating structure on LWC paper & Chinga and Helle (2002b) \\
\hline $\begin{array}{l}\text { FE-SEM and image } \\
\text { analysis }\end{array}$ & Coating structure characterization & Lee et al. (2018) \\
\hline $\begin{array}{l}\text { FE-SEM and image } \\
\text { analysis }\end{array}$ & $\begin{array}{l}\text { Effect of SB latex on the coating } \\
\text { structure }\end{array}$ & Lee and Lee (2018) \\
\hline $\mathrm{AFM}^{*}$ & Film formation of barrier latex & Rissa et al. (1999) \\
\hline AFM & Barrier-coating analysis & Vähä-Nissi et al. (2000) \\
\hline AFM & Latex-film formation in coatings & Kugge (2004) \\
\hline AFM & $\begin{array}{c}\text { Binder migration and ink } \\
\text { penetration }\end{array}$ & $\mathrm{Li}$ and $\mathrm{Gu}(2015)$ \\
\hline AFM & Binder distribution in the z-direction & Di Risio and Yan (2006) \\
\hline
\end{tabular}

\section{Mechanisms of binder migration}

Research on binder migration has been conducted for many years, and various theories have been proposed to explain why binder migrates. The modified capillary transport mechanism proposed by Hagen $(1986,1989)$ and the boundary-wall effect mechanism proposed by Ranger (1994) are most widely accepted, even though these two mechanisms contradict each other. Hagen $(1986,1989)$ proposed that latex particles are dragged to the surface by capillary flow when water evaporates. Hagen's capillary transport mechanism, however, fails to explain the fact that migration mainly takes place in the early stage of drying, before the formation of the first critical concentration (Watanabe and Lepoutre 1982; Engström et al. 1987; Zang et al. 2010). 
In contrast, Ranger (1994) suggested that the enrichment of latex binder at the surface is mainly due to the boundary wall effect of the coating applicator during coating application, which causes a near-wall depletion of particles. The strength of near-wall depletion decreases with decreasing particle size, which results in the enrichment of latex at the surface. In addition, the strength of depletion decreases as the particle concentration increases (Hartman Kok et al. 2002, 2004). The concentration of latex on the surface of a paper coating decreases as the solids content of the suspension increases (Krishnagopalan and Simad 1976; Watanabe and Lepoutre 1982; Yamazaki et al. 1993; Ranger 1994), which cannot be explained by the boundary wall mechanism. The boundary wall mechanism also contradicts the findings of some studies that have shown that nano-sized particles, including latex particles in paper coatings, mainly migrate to the surface after coating application (Watanabe and Lepoutre 1982; Luo et al. 2008).

More recently, Zang et al. (2010) proposed an alternative mechanism that attributes latex migration to differences in the Brownian mobility of particles and the surface trapping effect. Based on the Stokes-Einstein theory, the mechanism holds that particles with relatively small size have higher Brownian mobility than larger particles, and therefore these smaller particles diffuse more toward the air-water interface. In addition, water evaporation drives small particles toward the surface, where they accumulate due to the surface-trapping effect. However, this mechanism cannot quantitatively describe particle movements in a concentrated dispersion because collisions and interaction/flocculation between particles would invalidate the Stokes-Einstein theory developed for dilute dispersions. Thus, the Brownian motion of particles and the surface-trapping effect appear to play roles in binder migration. Before the drying of coating colors, latex particles move freely by Brownian motion, and the particles with a relatively small size tend to exhibit more Brownian motion. Due to the surface-trapping effect, however, the particles stop moving at the interface between the coating solution and air layer, which results in a higher binder concentration on the surface of the coating layer. Further studies are warranted to understand the exact mechanism of particle migration. Interestingly, binder migration plays a critical role in the manufacture of the lithium-ion rechargeable battery (Fig. 5).

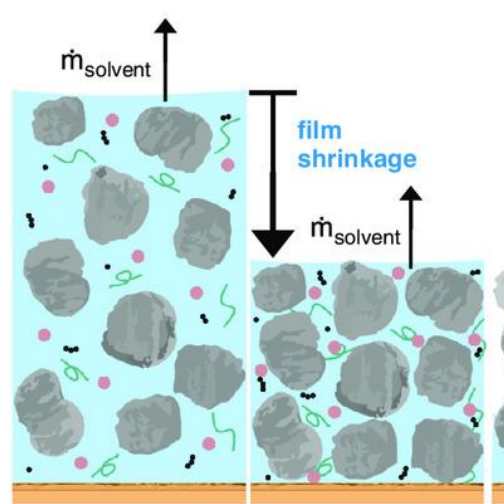

(a) wet film (b) filled capillary network

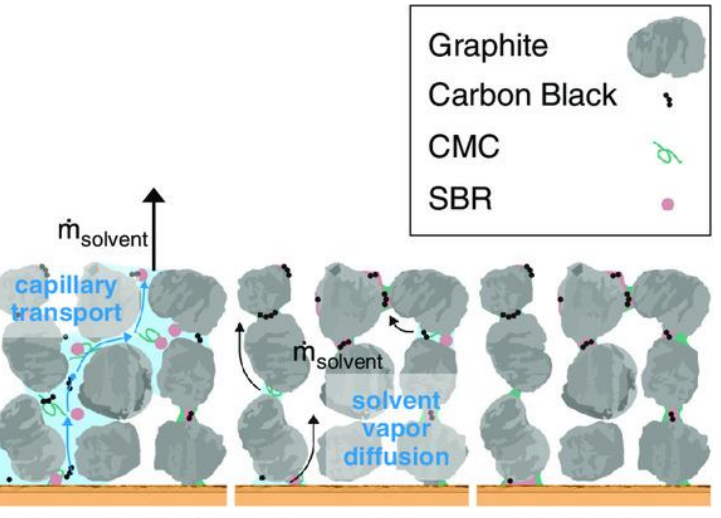

(c) partly filled (d) remaining capillary network liquid clusters (e) dry film

Fig. 5. A schematic of the drying process of lithium-ion battery anodes (Kumberg et al. 2019). Notice that styrene butadiene rubber (SBR) and carboxymethyl cellulose (CMC) migrate with the evaporating water, which results in uneven binder content in the thickness direction. The principle of binder migration and the mechanism of coating structure in pigment coating provide valuable explanation of the phenomena indicating the possibility of expanding the application of pigment coating to the new technology. 
The emerging applications in battery technology provide evidence that there are plenty of opportunities for the coating technologist to contribute in new industrial sectors.

\section{Drying Technology to Minimize Print Mottle}

Binder migration from the coating toward the base sheet occurs because water in the coating liquid moves toward the base paper and to the coating surface during coating application and consolidation. Binder migration itself does not lead to print mottle unless it results in a non-uniform binder distribution on the surface (Ragnarsson 2012). The influence of surface binder content on the print density and ink receptivity has been shown by Zang and Aspler (1998), Zhen and Wang (2013), and many others.

The water contained in the coating layer can move into the base paper by capillary absorption and application pressure and to the coating surface by evaporation during the drying process. Latex tends to move in the direction of water, either into absorbent base papers during application or to the coating surface during drying (Chattopadhyay 2014). Thus, binder migration depends on the amount of and speed with which water is absorbed into paper, and the amount of water that evaporates (Hagen 1986). When using the same drying process, if the solids content of the coating color is high, the binder migration decreases. Intensive drying conditions at high temperatures lead to greater binder migration, whereas mild drying conditions at lower temperatures yield a more uniform thickness profile of binder in the coating (Schut 1972; Zhen and Wang 2013).

If different areas of coating consolidate at different parts of the drying section, the coating structure becomes heterogenous, resulting in mottling of the printed image (Heikkilä and Rajala 2000). Aschan (1986) introduced the critical solids range that starts with the first local disappearance of free surface water and ends with the drying of the last surface pockets filled with wet coating. If a high drying rate is applied during the critical solids range at which small islands of dried surface coexist with alternating wet areas of coating, uneven binder migration will result, causing print mottle. Therefore, to suppress print mottling, it is necessary to keep the drying speed low from the moment the coating color begins to immobilize until the entire coating surface is immobilized. Näätsaari (2006) showed that the evaporation rate at the critical stage determines the level of mottle for a coating color with starch binder. When the solids content of the coating color is higher than the critical solids range or consolidation point, the latex particles cannot migrate because they are completely immobilized by pigment particles. In this case, the drying speed after the immobilization point has no influence on latex migration or on print mottle.

Three-zone drying has been suggested as a desirable low-speed drying method for use in the critical solids range, to minimize binder migration in the critical stage (Hagen 1986; Engström et al. 1991). However, in the case of woodfree colors, the theory of highlow-high drying rate is not applicable. In fact, to maintain the high drying rates in all three stages is more suitable to achieve uniform binder contents for coated and double-coated woodfree paper (Engström 2016). Rajala et al. (2004) showed that the use of an impingement dryer for initial drying provides better coating quality than the use of IR drying, and a high drying power in the first dryer using impingement dryer reduces print mottle and gives better gloss/smoothness results (Rajala et al. 2004). This means that less mottle results when the evaporation rate is high at the beginning of evaporation than when it is low. In contrast, Li et al. (2010) showed that a high drying temperature results in uneven binder distribution, which promotes print mottling. However, they did not evaluate the influence of the drying rate in the drying stage. 


\section{PREVENTIVE MEASURES FOR PRINT MOTTLE}

The uniformity of raw stock is of paramount importance. This includes its formation uniformity, surface smoothness, sizing uniformity, etc. Base paper with poor formation can result in uneven binder distribution in the coating layer, eventually resulting in an uneven, mottled print image (Pylkkoö 2000). This is generally attributable to the fact that uneven formation of the base paper results in variations in coat weight. If different areas of coating consolidate at different drying rates in different parts of the drying section, then the coating structure becomes heterogeneous, resulting in a mottled print image (Heikkilä and Rajala 2000). In addition, if the sizing degree of the base paper is not uniform, the absorption characteristics of the coating color will not be uniform, which will lead to non-uniform immobilization of the entire coating surface and eventually cause print mottling (Lee et al. 1997; Park and Lee 1998). Increasing the amount of coating solids is a useful way to decrease binder migration, especially starch migration (Yamazaki et al. 1993). Promoting the immobilization of printing ink is particularly effective for preventing back-trap mottle. To this end, it is necessary to increase micro-roughness on the surface of the coating layer and to keep the porosity of the coating layer high. To achieve this, it is preferable to use precipitated calcium carbonate or an appropriate plastic pigment. In some cases, a method to decrease the binder content may be used.

Latex binders that contain a low amount of butadiene show high ink-absorbency rates, due to their more open structure than binders that contain higher amounts of butadiene. Groves et al. (1993) showed that latex binder with butadiene content higher than $35 \%$ increases the vehicle penetration into the latex, which results in an increase of ink absorption. The importance of the S/B ratio was demonstrated by Purfeerst and van Gilder (1991), who tested the tail-edge picking, back-trap mottle, and fountain-solution interference depending on S/B ratios. They showed that latexes with a high glass-transition temperature $\left(T_{\mathrm{g}}\right)$ improved the tail-edge picking and decreased fountain-solution interference, while they showed more severe back-trap mottle. Yamazaki et al. (1993), who determined the latex content in a coating surface with ESCA, showed that high- $T_{\mathrm{g}}$ latex migrates more easily than low- $T_{\mathrm{g}}$ latex, which was more evident for high-coating-weight papers. The importance of the $T_{\mathrm{g}}$ of latex in binder migration has also been shown by Nowicki and Scriven (1990) and Kugge (2004). They showed clearly that greater migration occurs when a high- $T_{\mathrm{g}}$ latex is used; this was because high- $T_{\mathrm{g}}$ latex is less tacky or has a low tendency to adhere to pigments. In a separate research, Engström et al. (1987) reported that a low $T_{\mathrm{g}}$ latex is less likely to show print mottle, and they attributed to the fact that a low $T_{\mathrm{g}}$ latex shows little variation in ink absorption despite the variations in coat weight. However, this is effective only when the coat weight is less than $25 \mathrm{~g} / \mathrm{m}^{2}$. When the coat weight is higher than this, the positive effect of using low $T_{\mathrm{g}}$ latex decreases.

Kwon et al. (2019) showed that use of a styrene-acrylate latex containing hydroxyethyl methacrylate (HEMA) comonomer leads to more uniform print gloss and less mottling. They found that this is because HEMA comonomers generated a more uniform binder distribution on the coating surface and in the z-direction of the coating layer, which results in more uniform print-ink absorption and less print mottling. Oh et al. (2019) investigated the effect of the core-shell structure of styrene-acrylate latexes on the coating structure and print mottle and showed that a hard-shell latex with a high styrene content in its shell gives a higher gloss and less rough paper with finer pores, which results in an increased ink absorption rate and better printing uniformity and less mottling. 
It is advantageous to keep the distance from the blade to the drying section short, as this reduces the amount of water that penetrates from the coating color into the base paper before drying, thus yielding a more uniform binder distribution. Short dwell application (SDA) via blade coaters tends to generate less print mottling compared to long dwell application (LDA). This is because SDA prevents immobilization progressing to the coating surface until drying starts, and thus the coating solids across the entire coating surface remain below the immobilization point. In contrast, LDA allows the areas with low coat weight to reach a state of immobilization before drying starts, because of water absorption by the base paper. Thus, LDA creates two areas: an immobilized area and a non-immobilized area ink. Variations in coating weight and the interval period between coating and drying, i.e., the dwell time, result in differences in the starch content in the coated surface more easily than the latex content, which promotes print mottle (Yamazaki et al. 1993).

\section{CONCLUSIONS AND PERSPECTIVES}

The mechanism by which print mottle occurs in coated paper, and how the characteristics of the coated paper and the coating process relate to print mottle, have been examined in this review. It has focused mainly on coating structure, binder migration, and coat weight variation because these are the primary causes of print mottle in offset printing. An understanding of the printing process, and of ink absorption and fountain-water absorption, is essential to fully clarify the causes of and solutions for print mottling. Although extensive research efforts have been devoted to understanding print mottling over the past 50 years, many unanswered questions remain. This review suggests that achieving uniformity in the formation of base paper, the coating structure, and binder migration are critical for obtaining mottle-free paper.

Many technical developments, including not only in the paper and coating technology but also in the printing process and printing inks, have been made in the $21^{\text {st }}$ century especially in the USA and Europe to solve the print mottling of coated papers. In this review, the developments made in the pigment coating technology was reviewed. But it should be remembered that the final solution of printing should be found from the collaborative efforts of the papermaker, printer, and ink maker.

It is interesting to know that the scientific knowledge on the printing mottle, binder migration, and pigment coating structure can be applied to the development and manufacturing of the rechargeable battery. For example, among rechargeable batteries, the lithium-ion batteries use almost the same principle as in pigment coating. Binder migration, drying cracking of the coating layer, and many other phenomena associated with the lithium-ion batteries can be explained based on the knowledge of the pigment coating, which will provide new opportunities for pigment coating technologists in improving not only the processing but also the quality of the rechargeable lithium-ion batteries.

\section{REFERENCES CITED}

Alm, H. K., Ström, G., Schoelkopf, J., and Gane, P. (2015). "Ink-lift-off during offset printing: A novel mechanism behind ink-paper coating adhesion failure," J. Adhes. Sci. Technol. 29(5), 370-391. DOI: 10.1080/01694243.2014.989650 
Anayath, R., and Baral, A. K. (2016). "Critical analysis of mottling and its impact on various grades of paper substrates printed under conventional sheet fed offset, dry toner \& liquid toner based digital print engines," Acta Graphica 27(1), 7-14.

Anttila, M., Hakkila, O., and Enso, S. (2009). "Mottling in offset printing," in: Proceedings of PaperCon '09, St. Louis, MO, USA, pp. 1-15.

Arai, T. (1989). "Relationship between coating structure and print mottle," TAPPI J. Japan 43(3), 57-66. DOI: 10.2524/jTAPPIj.43.319

Arai, T., Yamasaki, T., Suzuki, K., Ogura, T., and Sakai, Y. (1988). “The relationship between print mottle and coating structure," TAPPI J. 71(5), 47-52.

Aschan, P. (1986). "Solving problems of print mottle on coated board," TAPPI J. 69(12), 35-38.

Aspler, J. S., and Lepoutre, P. (1991). "The transfer and setting of ink on coated paper: A review," in: Proceedings of CPPA 1991 Paper Coating Fundamentals Symposium, Montreal, Canada, pp. 77-98.

Backfolk, K., Grankvist, T., Ghosh, T., Astola, J., Sinervo, L., and Luttikhedde, T. (2006). "The effect of water retention and rheology modifiers on the formation of coating structure and migration of particles," in: Proceedings of 2006 TAPPI Advanced Coating Fundamentals Symposium, Turku, Finland, pp. 311-321.

Bassemir, R. W. (1982). "Surface chemistry and the lithographic process," in: Colloids and Surfaces in Reprographic Technology, M. Hair and M. D. Croucher (eds.), ACS Symposium Series, Washington D.C., USA, pp. 327-345.

Baumeister, M., and Kraft, K. (1980). "Quality optimization by control of coating structure," in: Proceedings of the TAPPI Coating Conference, Miami Beach, FL, USA, pp. 11-22.

Bitla, S., Tripp, C. P., and Bousfield, D. W. (2003). "A Raman spectroscopic study of migration in paper coatings," J. Pulp Pap. Sci. 29(11), 382-385.

Bruno, M. H., and Walker, W. C. (1983). "Printing," in: Pulp and Paper: Chemistry and Chemical Technology, J. P. Casey (ed.), Wiley, New York, NY, USA, pp. 2191-2248.

Bushhouse, S. G. (1990). "The effect of coating viscosity on surface latex concentration," TAPPI J. 75, 231-237.

Chattopadhyay, R. (2014). Dynamics of Particle Movements in Paper Coatings, Ph.D. Dissertation, University of Maine, Orono, ME, USA.

Chinga, G., and Helle, T. (2002a). "Structure characterization of pigment coating layer on paper by scanning electron microscopy and image analysis," Nord. Pulp Pap. Res. J. 17(3), 307-312. DOI: 10.3183/npprj-2002-17-03-p307-312

Chinga, G., Helle, T., and Forseth, T. (2002b). "Quantification of structure details of LWC paper coating layers," Nord. Pulp Pap. Res. J. 17(3), 313-318. DOI: 10.3183/npprj-2002-17-03-p313-318

Chinga, G., and Helle, T. (2003). "Relationships between the coating surface structural variation and print quality," J. Pulp Pap. Sci. 29(6), 179-184.

Dahlström, C., and Uesaka, T. (2012). "Microstructure variations in paper coating: Direct observations," Ind. Eng. Chem. Res. 51(24), 8246-8252. DOI: 10.1021/ie202874z

Dappen, J. W. (1951). "Distribution of starch in clay coatings," TAPPI J. 34(7), 324-335.

Di Risio, S., and Yan, N. (2006). "Characterizing coating layer z-directional binder distribution in paper using atomic force microscopy," Colloid. Surface. A 289(1-3), 65-74. DOI: 10.1016/j.colsurfa.2006.04.007

Donigian, D. W., Ishley, J. N., and Wise, K. J. (1997). “Coating pore structure and offset printed gloss," TAPPI J. 80(5), 163-172. 
Donigian, D. W., Vyörykkä, J., and Xiang, Y. (2004). "The relationship between ink setting rates, backtrap piling and micro-picking," in: 2004 Coating and Graphic Arts Conference, Baltimore, MA, pp. 217-229.

Eby, T., and Whalen-Shaw, M. (1991). "A study of back-trap mottle in coated papers using electron probe microanalysis," TAPPI J. 74(12), 188-194.

Eklund, D. E., and Salminen, P. J. (1986). "Water transport in the blade coating process," TAPPI J. 69(9), 116-119.

The Contributors of Encyclopedia Britannica (1998). "Offset printing," (https://www.britannica.com/technology/offset-printing), Accessed 10 March 2021.

Engström, G., Norrdahl, P., and Ström, G. (1987). "Studies of the drying and its effect on binder migration and offset mottling," TAPPI J. 70(12), 45-49.

Engström, G., Rigdahl, M., Kline, J., and Ahlroos, J. (1991). "Binder distribution and mass distribution of the coating layer - Cause and consequence," in: 1991 Coating Conference Proceedings, Montreal, Canada, pp. 171-179.

Engström, G. (1994). "Formation and consolidation of a coating layer and the effect on offset-print mottle," TAPPI J. 77(4), 160-172.

Engström, G. (2016). "Causes of back-trap mottle in lithographic offset prints on coated papers," TAPPI J. 15(2), 91-101.

Fahlcrantz, C.-M., and Johansson, P.-A. (2004). "A comparison of different print mottle evaluation models," in: $56^{\text {th }}$ Annual Technical Conference of the Technical Association of the Graphic Arts, San Antonio, TX, USA, pp. 511-525.

Fardim, P., and Holmbon, B. (2003). "Chemical microscopy of paper surfaces," in: $5^{\text {th }}$ International Paper and Coating Symposium, Montreal, Quebec, Canada, pp. 269273.

Fujiwara, H., and Kline, J. E. (1987). "Ultraviolet absorption of styrene-butadiene latex on pigment-coated paper," TAPPI J. 70(12), 97-100.

Gane, P. A. C. (1989). "Mottle and the influence of coating and binder migration," Paper Technology 30(4), 34-41.

Groves, R., Penson, J. E., and Ruggles, C. (1993). "Styrene-butadiene latex binders and coating structure," in: Proceedings of the 1993 Coatings Conference, Minneapolis, MN, USA, pp. 187-187.

Groves, R., Matthews, G. P., Heap, J., McInnes, M. D., Penson, J. E., and Ridgway, C. J. (2001). "Binder migration in paper coatings - A new perspective," in: The Science of Papermaking: Transactions of the 12th Fundamental Research Symposium Oxford 2001, C. F. Baker (ed.) FRC, Manchester, UK, pp. 1149-1181.

Gumbel, R. (2003). "Produktivitäts Kriterien und Papiereigenschaften im Offsetdruck [Productivity criteria and paper properties in offset printing]," Int. Papierwirtschaft 4, $38-42$.

Hagen, K. G. (1986). "A fundamental assessment of the effect of drying on coating quality," TAPPI J. 69(1), 93-96.

Hagen, K. G. (1989). "Using infrared radiation to dry coatings," TAPPI J. 72(5), 79-84. Hakola, E. (2009). "Principles of conventional printing," in: Print Media - Principles, Processes and Quality, P. Oittinen and H. Saarelma (eds.), Paperi ja Puu Oy, Espoo, Finland, pp. 42-87.

Halttumen, M., Stenius P., Löija, M., Tenhumen, J., Vuorinen, T., and Kenttä E. (2001). "Determination of SB-latex distribution at paper coating surfaces with FTIR/ATR spectroscopy," in: Proceedings of the TAPPI Coating and Graphic Arts Conference, San Diego, CA, USA, pp. 203-211. 
Hartman Kok, P. J. A., Kazarian, S. G., Lawrence, C. J., and Briscoe, B. J. (2002). "Nearwall particle depletion in a flowing colloidal suspension," J. Rheol. 46(2), 481-493. DOI: $10.1122 / 1.1446882$

Hartman Kok, P. J. A., Kazarian, S. G., Briscoe, B. J., and Lawrence, C. J. (2004). "Effects of particle size on near-wall depletion in mono-dispersed colloidal suspensions," J. Colloid Interf. Sci. 280(2), 511-517. DOI: 10.1016/j.jcis.2004.08.032

Heikkilä, P., and Rajala, P. (2000). "Drying of paper coatings and drying equipment," in: Pigment Coating and Surface Sizing of Paper, J. Paltakari (ed.), Paper ja Puu Oy, Espoo, Finland, pp. 543-565.

ISO 13660 (2001). "Information technology - Office equipment - Measurement of image quality attributes - Binary monochrome text and graphic images," International Organization for Standardization, Geneva, Switzerland.

Järnström, J., Väisänen, M., Lehto, R., Jäsberg, A., Timonen, J., and Peltonen, J. (2010). "Effect of latex on surface structure and wetting of pigment coatings," Colloid. Surface. A 353(2-3), 104-116. DOI: 10.1016/j.colsurfa.2009.11.001

Kasajová, M., and Gigac, J. (2020). "Comparison of print mottle and surface topography testing methods," Nord. Pulp Pap. Res. J. 28(3), 443-449. DOI: 10.3183/npprj-201328-03-p443-449

Kenttä, E., Juvonen, K., and Vyörykkä, J. (2000). "Spectroscopic methods for determination of latex content of coating layers," Nord. Pulp Pap. Res. J. 15(5), 579585. DOI: 10.3183/npprj-2000-15-05-p579-585

Kenttä, E., Pöhler, T., and Juvonen, K. (2006) "Latex uniformity in the coating layer of paper,” Nord. Pulp Pap. Res. J. 21(5), 665-669. DOI: 10.3183/npprj-2006-21-05p665-669

Kim, L., Pollock, M., and Wittbrodt, E. (1998). "Reduction of back-trap mottle through optimization of the drying process for paper coatings, Part I," TAPPI J. 81(8), 153164.

Kim-Habermehl, L., Pollock, M., Wittbrodt, E., Roper, J., McCoy, J., Stolarz, J., Langolf, B., and Rolf, M. (1998). "Characterization of coated paper surface morphology and its correlation to print mottle," in: Proceedings of Pan-Pacific and International Printing and Graphics Arts Conference, Quebec City, Quebec, Canada, pp. 71-76.

Klein, R., Miletic, M., Meder, G., Eckert, D., and Grossmann, H. (2011a). "Influence of paper properties on mottling in sheet offset. Part 1: Pressure test and evaluation," Wochenbl. Papierfabr. 139(5), 324-328.

Klein, R., Miletic, M., Meder, G., Eckert, D., and Grossmann, H. (2011b). "Influence of paper properties on mottling in sheet offset. Part 2: Paper review and case analysis," Wochenbl. Papierfabr. 139(6), 464-471.

Kline, J. E. (1988). "The use of ultraviolet analysis on coated paper," in: TAPPI Coating Conference Proceedings, New Orleans, LA, USA, pp. 67-72.

Kline, J. E. (1991). "Measuring binder migration with ultraviolet analysis," TAPPI J. 74(4), 177-182.

Kolseth, P. (2009). "Printing as a means of paper testing," in: Symposium Platte und Papier, Hochschule der Medien, Stuttgart, Germany, pp. 1-80.

Krishnagopalan, A., and Simad, G. L. (1976). "An improved technique for studying binder migration in coated paper," TAPPI J. 59(12), 96-99.

Kugge, C. (2004). "An AFM study of local film formation of latex in paper coatings," $J$. Pulp Pap. Sci. 30(4), 105-111. 
Kumberg, J., Müller, M., Diehm, R., Spiegel, S., Wachsmann, C., Bauer, W., Scharfer, P., and Schabel, W. (2019). "Drying of lithium-ion battery anodes for use in highenergy cells: Influence of electrode thickness on drying time, adhesion, and crack formation," Energy Technol. 2019(3), 1900722. DOI: 10.1002/ente.201900722

Kwon, S., Oh, K., Shin, S. J., and Lee, H. L. (2019). "Structural changes of coating layer by styrene/acrylate latex with hydroxyethyl methacrylate," ACS Omega 4(19), 1840518412. DOI: 10.1021/acsomega.9b02671

Lee, H. L. (1992). "Coating structure and ink absorption properties of coated paper affected by coating formulation (2) - Ink absorption properties," J. Korea TAPPI 24(4), 26-35.

Lee, D. I., and Whalen-Shaw, M. J. (1993). "Fundamentals and strategies," in: Binder Migration in Paper and Paperboard Coating, M. J. Whalen-Shaw (ed.), TAPPI Press, Atlanta, GA, USA, pp. 19-28.

Lee, H. L., Shin, D. S., and Chung, J. K. (1997). "Development of paper coating technologies to prevent print mottle (III) - Evaluation of ink absorption properties of coated papers and prediction of print mottle," J. Korea TAPPI. 29(3), 60-68.

Lee, H. L. (2008). "Print mottle: Causes and solutions from paper coating industry perspective," J. Korea TAPPI 40(5), 60-69.

Lee, J.-H., Oh, K., Rajabi Abhari, A., and Lee, H. L. (2018). "Characterization of paper coating structure using FIB and FE-SEM. 1. A new method for image analysis," Ind. Eng. Chem. Res. 57(12), 4237-4244. DOI: 10.1021/acs.iecr.7b04673

Lee, J.-H., and Lee, H. L. (2018). "Characterization of the paper coating structure using focused ion beam and field-emission scanning electron microscopy. 2. Structural variation depending on the glass transition temperature of an S/B Latex," Ind. Eng. Chem. Res. 57(49), 16718-16726. DOI: 10.1021/acs.iecr.8b04802

Li, Y., He, B.-H., Meng, Y.-L., and Li, Y. (2010). "Investigation into the effect of binder on print quality of coated paper," in: Proceedings of the $17^{\text {th }}$ IAPRI World Conference on Packaging, Tianjin, China, pp. 184-187.

Li, Y., and Gu, W. J. (2015). "Characterising the effect of binder migration on ink penetration using reconstructed images by atom force microscopy and laser scanning confocal microscopy," Mater. Res. Innov. 19(5), 988-992. DOI: 10.1179/1432891714Z.0000000001235

Li, J. G., and Li, Y. (2014). "Investigation into the influence of drying on backtrap mottle of coated paper," Adv. Mat. Res. 904, 373-376. DOI:

10.4028/www.scientific.net/amr.904.373

Lie, C., and Kolseth, P. (2007). "Aspects on water-induced mottle when printing on coated paper in sheet-fed lithographic offset," in: Advances in Printing and Media Technology, N. Enlund, and M. Lovrecek (eds.), Acta Graphica, Zagreb, Croatia, pp. 59-67.

Lovreček, M., Miroslav, G., and Dragčević, K. (1998). "Interfacial characteristics of the rubber blanket: Dampening solution system," Adv. Pr. Sci. 25, 103-114.

Luo, H., Cardinal, C. M., Scriven, L. E., and Francis, L. F. (2008). “Ceramic nanoparticle/monodisperse latex coatings," Langmuir 24(10), 5552-5561. DOI: $10.1021 / 1 \mathrm{a} 800050 \mathrm{u}$

Lyne, M. B. (1979). "Multidimensional scaling of print quality," TAPPI J. 62(11), 103107.

MacPhee, J. (1979). “An engineer's analysis of the lithographic printing process," in: Proceedings of 1979 TAGA Annual Meeting, Kansas City, MO, USA, pp. 237-277. 
Matsubayashi, H., and Satio, Y. (1992). "The influence of coating structure on paper quality," in: TAPPI Coatings Conference Proceedings, TAPPI Press, Atlanta, GA, USA, pp. 161-171.

Näätsaari, M. (2006). Coat Weight and Drying Power Control, Final Thesis, Tampere University of Applied Sciences, Tampere, Finland.

Norrdahl, P. C. (1991). "Effect of drying conditions on paper quality on wood-containing lightweight coated paper," TAPPI J. 74(5), 73-78.

Nowicki, S. C., and Scriven, L. E. (1990). "On the physics of drying and binder migration in coated papers," in: TAPPI Coatings Conference Proceedings, Boston, MA, USA, pp. 49-63.

Oh, K., Rajabi Abhari, A., Im, W., Lee, J.-H., Shen, Z., Kwon, S., Yeu, S. U., and Lee, H. L. (2019). "Effect of core-shell structure latex on pigment coating properties," BioResources 14(1), 1241-1251. DOI: 10.15376/biores.14.1.1241-1251

Oittinen, P. (1976). "Fundamental rheological properties and tack of printing inks and their influence on ink behavior in a printing nip," Acta Polytech. Scand. 131, 1-192.

Oittinen, P., and Saarelma, H. (2009). "Mechanisms of printing," in: Print Media Principles, Processes and Quality, P. Oittinen and H. Saarelma (eds.), Paperi ja Puu Oy, Espoo, Finland, pp. 88-147.

Ozaki, Y., Bousfield, D. W., and Shaler, S. M. (2008). "Characterization of coating layer structural and chemical uniformity for samples with backtrap mottle," Nord. Pulp Pap. Res. J. 23(1), 8-13. DOI: 10.3183/NPPRJ-2008-23-01-p008-013

Paltakari, J., Lehtinen, E., and Imppola, O. (2009). "Introduction to pigment coating and surface sizing of paper and board," in: Pigment Coating and Surface Sizing of Paper, J. Paltakari (ed.), Paperi ja Puu Oy, Espoo, Finland, pp. 11-28.

Pang, Y. C., Li, Z. J., and Shi, L. L. (2015). "Study on relationship of ink thickness and color saturation," Appl. Mech. Mater. 731, 295-299. DOI: 10.4028/www.scientific.net/amm.731.295

Park, C. W., and Lee, H. L. (1998). "Coagulation of cationic rosin emulsion and its effect on ink receptivity of coating layer," J. Korea TAPPI 30(3), 73-83.

Preston, J., Hiorns, A. G., Elton, N., and Strom, G. (2008). "Application of imaging reflectometry to studies of print mottle on commercially printed coated papers," TAPPI J. 7(1), 11-18.

Purfeerst, R. D., and van Gilder, R. L. (1991). "Tail-edge picking, back-trap mottle and fountain solution interference of model latex coatings on a six-colour press," in: Proceedings of 1991 Coating Conference, Montreal, Canada, pp. 461-472.

Pylkkoö, J. (2000). "Mechanical base paper," in: Pigment Coating and Surface Sizing of Paper, J. Paltakari (ed.), Paperi ja Puu Oy, Espoo, Finland, pp. 29-44.

Ragnarsson, M. (2012). Variations Related to Print Mottle in Starch-Containing Paper Coatings, Ph.D. Dissertation, Karlstad University, Karlstad, Sweden.

Ragnarsson, M., Engström, G., and Järnström, L. (2013). "Coating: Porosity variations in coating layers - Impact on backtrap mottle,” Nord. Pulp Pap. Res. J. 28(2), 257-263. DOI: 10.3183/npprj-2013-28-02-p257-263

Rajala, P., Milosavljevic, N., Kiiskinen, H., and Hendrickson, M. (2004). "The effect of the impingement air drying on print mottle and other coated paper properties," Appl. Therm. Eng. 24(17-18), 2527-2536. DOI: 10.1016/j.applthermaleng.2004.03.015

Ranger, A. E. (1994). "Binder migration during drying of pigment coatings," Pap. Technol. 35(12), 40-46. 
Resch, P., Bauer, W., and Hirn, U. (2010). "Calendering effects on coating pore structure and ink setting behavior," TAPPI J. 9(1), 27-35. DOI: 10.32964/tj9.1.27

Rissa, K., Vähä-Nissi, M., Savolainen, A., and Lepistö, T. (1999). “Application of atomic force microscopy in pigment and dispersion coating analysis," in: Proceedings of the 1999 Advanced Coating Fundamentals Symposium, Toronto, Canada, pp. 175-189

Sandreuter, N. P. (1994). "Predicting print mottle: A method of differentiating between three distinctively different types of mottle: Backtrap mottle, water sensitivity mottle, and wet ink trapping mottle," in: TAPPI Coating Conference Proceedings, TAPPI Press, Atlanta, GA, USA, pp. 211-228.

Saini, A., Jangra, V., and Jain, A. (2016a). "Study of print mottle in sheet-fed offset printing," Int. Res. J. Eng. Tech. Res. 3(5), 1825-1832.

Saini, A., Jangra, V., and Jain, A. (2016b). "Analysis of print mottle in sheet-fed offset and digital printing," Int. Res. J. Eng. Tech. Res. 4(3), 141-144.

Salminen, P., Roper, J., Pollock, M., and Chonde, Y. (1995). "Determining the dynamic water retention contribution of various cobinders and thickeners," in: TAPPI Coating Conference Proceedings, Dallas, TX, USA, pp. 277-286.

Schut, G. R. (1972). "A study of different drying systems and the influence of their variables on the quality of coated papers," Wochenbl. Papierfabr. 100(2), 48-58.

Shen, Y., Bousfield, D. W., van Heiningen, A., and Donigian, D. (2005). "Linkage between coating absorption uniformity and print mottle," J. Pulp Pap. Sci. 31(3), 105-108.

Ström, G., and Carlsson, G. (1993). "Chemical composition of coated paper surfaces determined by means of ESCA," Nord. Pulp Pap. Res. J. 8(1), 105-112. DOI: 10.3183/npprj-1993-08-01-p105-112

Thorman, S., Ström, G., and Gane, P. A. C. (2018). "Impact of non-uniform water absorption on water-interference print mottle in offset printing," Nord. Pulp Pap. Res. J. 33(1), 150-163. DOI: 10.1515/npprj-2018-3011

Tomimasu, H., Ogawa, S., Sakai, Y., Yamasaki, T., and Ogura, T. (1986). "ESCA to analyze surface binder concentration of coated paper," in: Proceedings of Coating Conference, TAPPI Press, Atlanta, GA, USA, pp. 35-43.

Tomimasu, H., Suzuki, K., Ogura, T., and Luner, P. (1990). "The effect of basestock structure on coating weight distribution," TAPPI J. 73(5), 179-187.

Vähä-Nissi, M., Rintanen, J., Lahti, J., Savolainen, A., Rissa, K., and Lepistö, T. (2000). "Characterization of barrier clay coatings using AFM and SEM," in: Proceedings TAPPI Coating Conference and Trade Fair, Washington D.C., USA, pp. 271-283. van Gilder, R. L., and Purfeerst, R. D. (1994). "Latex binder modification to reduce coating pick on six-color offset presses," TAPPI J. 77(5), 230-239.

Voltaire, J. (2004). Ink Film Splitting Acoustics and Tack on Paper in Offset Printing, Licentiate Thesis, KTH Royal Institute of Technology in Stockholm, Stockholm, Sweden.

Vyörykkä, J., Halttunen, M., Iitti, H., Kenttä, E., Paaso, J., Tenhunen, J., Vuorinen, T., and Stenius, P. (2001). "Confocal-Raman analysis method to study binder depth profiles in coating layers," in: Proceedings TAPPI Coating and Graphic Arts Conference and Trade Fair, Washington D.C., USA, pp. 193-201.

Vyörykkä, J., Vuoinen, T., and Bousfield, D. W. (2004a). "Confocal Raman microscopy: A non-destructive method to analyze depth profiles of coated and printed papers," Nord. Pulp Pap. Res. J. 19(2), 218-223. DOI: 10.3183/npprj-2004-19-02-p218-223 
Vyörykkä, J., Juvonen, K., Bousfield, D. W., and Vourinen, T. (2004b). "Raman microscopy in lateral mapping of chemical and physical composition of paper coating," TAPPI J. 3(9), 19-24.

Watanabe, J., and Lepoutre, P. (1982). "A mechanism for the consolidation of the structure of clay-latex coatings," J. Appl. Polym. Sci. 27(11), 4207-4219. DOI: 10.1002/app.1982.070271112

Whalen-Shaw, M. J. (1993). Binder Migration in Paper and Paperboard Coatings, M. J. Whalen-Shaw (ed.), TAPPI Press, Atlanta, GA, USA.

Whalen-Shaw, M., and Eby, T. (1991). "An investigation of factors related to backtrap mottle in coated papers using electron probe microanalysis," in: TAPPI Coating Conference Proceedings, Montreal, Quebec, Canada, pp. 401-409.

Xiang, Y., Bousfield, D. W., Hassler, J., Coleman, P., and Osgood, A. (1999). "Measurement of local variation of ink tack dynamics," J. Pulp Pap. Sci. 25(9), 326-330.

Xiang, Y., Bousfield, D. W., Coleman, P., and Osgood, A. (2000). "The cause of backtrap mottle: Chemical or physical?," in: Proceedings of 2000 Coating Conference, Washington D.C., USA, pp. 45-58.

Xu, Y., Liang, Q., Wang, Q., Liu, G., and Li, L. (2016). “Analysis and evaluation model for print mottle using wavelet image denoising method," BioResources 11(4), 96499660. DOI: 10.15376/biores.11.4.9649-9660

Yamazaki, K., Nishioka, T., Hattori, Y., and Fujita, K. (1993). "Print mottle effect of binder migration and latex film formation during coating consolidation," TAPPI J. 76(5), 79-84.

Zang, Y. H., and Aspler, J. S. (1995). "Influence of coating structure on the ink receptivity and print gloss of model clay coatings," TAPPI J. 78(1), 147-154.

Zang, Y. H., and Aspler, J. S. (1998). "The effect of surface binder content on print density and ink receptivity of coated paper," TAPPI J. 24(5), 141-145.

Zang, Y. H., Du, J., Du, Y., Wu, Z., Cheng, S., and Liu, Y. (2010). “The migration of styrene butadiene latex during the drying of coating suspensions: When and how does migration of colloidal particles occur?," Langmuir 26(23), 18331-18339. DOI: 10.1021/la103675f

Zhen, Z. H., and Wang, Z. S. (2013). "Coating binder migration and affected parameters: Influence of pigments and base paper," Adv. Mat. Res. 791-793, 192-195. DOI: 10.4028/www.scientific.net/AMR.791-793.192

Zimmerman, P. A., Hercules, D. M., Rulle, H., Zehnpfenning, J., and Benninghoven, A. (1995). "Direct analysis of coated and contaminated paper using time-of-flight secondary ion mass spectrometry," TAPPI J. 78(2) 180-186.

Article submitted: February 22, 2021; Peer review completed: May 9, 2021; Revised version received and accepted: May 25, 2021; Published: June 15, 2021.

DOI: 10.15376/biores.16.3.Lee 